\title{
SURVIVAL RELATED TO LYMPH NODE INVOLVEMENT IN LUNG CANCER AFTER SLEEVE LOBECTOMY COMPARED WITH PNEUMONECTOMY
}

\author{
Morihito Okada, MD \\ Hiroyuki Yamagishi, MD \\ Shinsuke Satake, MD \\ Hidehito Matsuoka, MD \\ Yoshifumi Miyamoto, MD \\ Masahiro Yoshimura, MD \\ Noriaki Tsubota, MD
}

Objective: The purpose of this study was to compare the outcomes after sleeve lobectomy and pneumonectomy for patients with non-small cell lung cancer distributed according to their nodal involvement status.

Methods: Of 1172 patients in whom primary non-small cell lung carcinoma, including mediastinal lymph nodes, was completely excised, 151 patients underwent sleeve lobectomy and 60 underwent pneumonectomy. For bias reduction in comparison with a nonrandomized control group, we paired 60 patients undergoing sleeve lobectomy with 60 patients undergoing pneumonectomy by using the nearest available matching method.

Results: The 30-day postoperative mortality was $2 \%(1 / 60)$ in the pneumonectomy group and $0 \%$ in the sleeve lobectomy group. Postoperative complications occurred in $13 \%$ of patients in the sleeve lobectomy group and in $22 \%$ of those in the pneumonectomy group. Local recurrences occurred in $8 \%$ of patients in the sleeve lobectomy group and in $10 \%$ of those in the pneumonectomy group. The overall 5- and 10-year survivals for the sleeve lobectomy group were $48 \%$ and $36 \%$, respectively, whereas those for the pneumonectomy group were $28 \%$ and $19 \%$, respectively $(P=.005)$. Multivariable analysis showed that the operative procedure, $\mathrm{T}$ factor, and $\mathrm{N}$ factor were significant independent prognostic factors and revealed that survival after sleeve lobectomy was significantly longer than that after pneumonectomy $(P=.03)$.

Conclusions: These data suggest that sleeve lobectomy should be performed instead of pneumonectomy in patients with non-small cell lung cancer regardless of their nodal status whenever complete resection can be achieved because this is a lung-saving procedure with lower postoperative risks and is as curative as pneumonectomy. (J Thorac Cardiovasc Surg 2000;119:814-9)
$P^{a}$ eumonectomy, as compared with lobectomy, is associated with higher occurrence of postoperative complications, poor quality of life, and cardiopulmonary dysfunction. In addition, long-term complications (ie, the so-called postpneumonectomy syndrome presenting as late pulmonary hypertension or respiratory failure)

From the Department of Thoracic Surgery, Hyogo Medical Center for Adults, Akashi City, Hyogo, and the Department of Thoracic Surgery, National Hyogo Central Hospital, Sanda City, Hyogo, Japan.

Received for publication June 22, 1999; revisions requested Aug 31, 1999; revisions received Nov 1, 1999; accepted for publication Nov 23, 1999.

Address for reprints: Noriaki Tsubota, MD, Department of Thoracic Surgery, Hyogo Medical Center for Adults, Kitaohji-cho 13-70, Akashi City 673, Hyogo, Japan (E-mail: n-tsubo@sanynet.ne.jp). Copyright $\odot 2000$ by The American Associatiion for Thoracic Surgery. 0022-5223/2000 $\$ 12.00+0 \quad \mathbf{1 2 / 1 / 1 0 4 5 7 9}$

doi: $10.1067 / \mathrm{mtc} .2000 .104579$ are sometimes associated with pneumonectomy but seldom seen after lobectomy. Therefore pneumonectomy itself is thought to be a disease. Sleeve lobectomy, which allows preservation of functional lung parenchyma with the possible advantages of lower mortality and morbidity, is a valid alternative to pneumonectomy and is accepted as one of the standard treatments for lung cancer. ${ }^{1-3}$ We therefore have performed it frequently and actively in noncompromised patients or in patients with $\mathrm{N} 2$ disease., ${ }^{4,5}$ However, the long-term results after sleeve lobectomy remain controversial, especially in relation to nodal involvement. There have been only a few studies in which sleeve lobectomy and pneumonectomy have been compared with regard to survival according to nodal status, and the number of patients in the subgroup related to nodal status was small., 3

We have reviewed our experience to compare sleeve lobectomy and pneumonectomy for non-small cell lung 
cancer in terms of survival and to determine significant factors related to survivals with special emphasis on nodal involvement.

\section{Patients and methods}

Of 1370 patients who underwent operation for primary non-small cell lung cancer between June 1984 and December 1998, 1172 patients underwent curative surgery. Curative surgery was defined as complete removal of ipsilateral hilar and mediastinal lymph nodes together with the primary tumor. Sleeve lobectomy was done in 151 patients, standard (nonsleeve) lobectomy in 815 , segmentectomy in 176 , and pneumonectomy in 60 . Sleeve lobectomy was usually done by choice in patients who would have been able to tolerate pneumonectomy but in whom the tumor could not have been removed by standard lobectomy and could be completely resected by a bronchoplastic procedure. Concomitant sleeve resection of the pulmonary artery (double sleeve resection) was required in 21 patients. Routine systematic dissection of all hilar and mediastinal nodes was performed in every case, even if the preoperative evaluation was N0 or N1. Every node dissected en bloc (not sampled) was examined by pathologists to be diagnosed as microscopically positive (cancerous) or negative (normal) during and after the operation. Patients who had evidence of residual tumor at the surgical margin, malignant effusion, or N3 disease verified by intraoperative findings or postoperative pathologic examination were considered to have undergone noncurative surgery ${ }^{7}$ and were excluded from this study. Local recurrence was defined as any recurrence in the ipsilateral hemithorax. Operative mortality was defined as 30-day postoperative mortality plus intraoperative mortality. Resected specimens were examined histopathologically, and histologic typing was done according to the World Health Organization classification. ${ }^{8}$ Surgical-pathologic staging was performed according to the New International Staging System for Lung Cancer. ${ }^{9}$

To reduce the bias in the comparison of a nonrandomizcd control group, we paired the sleeve lobectomy group with the pneumonectomy group by using the nearest available matching method on the estimated propensity score. ${ }^{10}$ Table I shows the characteristics of sleeve lobectomy and pneumonectomy groups. Categoric variables were analyzed by means of $\chi^{2}$ analysis and the unpaired $t$ test. Survival was estimated by means of the Kaplan-Meier method, ${ }^{11}$ and differences in survival were determined by means of log-rank analysis. The results of the multivariable analysis of independent prognostic factors, which included sex, histologic type, $\mathrm{T}$ factor, $\mathrm{N}$ factor, and operative procedure, were assessed by using the Cox proportional hazards regression model. ${ }^{12}$ Zero time was the date of pulmonary resection, and the terminal event was death attributable to cancer, a cause other than cancer, or an unknown cause. Operative mortality was included.

\section{Results}

Overall follow-up ranged from 9 to 174 months, with a median of 69 months. No patients with sleeve lobec-
Table I. Sleeve lobectomy and pneumonectomy groups paired by the nearest available matching method on the estimated propensity score

\begin{tabular}{lccc}
\hline & Sleeve lobectomy & Pneumonectomy & P value \\
\hline No. & 60 & 60 & \\
Sex & & & .8 \\
Male & $52(87 \%)$ & $53(88 \%)$ & \\
Female & $8(13 \%)$ & $7(12 \%)$ & .9 \\
Age* & $60.9 \pm 9.5$ & $60.6 \pm 9.0$ & .9 \\
Histologic type & & & \\
SQ & $36(60 \%)$ & $34(57 \%)$ & \\
AD & $21(35 \%)$ & $21(35 \%)$ & \\
AS & $2(3 \%)$ & $3(5 \%)$ & \\
LA & $2(3 \%)$ & $2(3 \%)$ & \\
pT factor & & & \\
T1 & $12(20 \%)$ & $10(17 \%)$ & \\
T2 & $19(32 \%)$ & $18(30 \%)$ & \\
T3 & $19(32 \%)$ & $17(28 \%)$ & \\
T4 & $10(17 \%)$ & $15(25 \%)$ & \\
pN factor & & & \\
N0 & $14(23 \%)$ & $12(20 \%)$ & \\
N1 & $16(27 \%)$ & $17(28 \%)$ & \\
N2 & $30(50 \%)$ & $31(52 \%)$ & \\
\hline
\end{tabular}

$S Q$, Squamous cell carcinoma; $A D$, adenocarcinoma; $A S$, adenosquamous carcinoma; $L A$, large cell carcinoma.

*Mean \pm SD.

tomy died within 30 days after the operation, and one patient with pneumonectomy died of pulmonary infarction on the day after the operation (operative mortality, $2 \%$ ). Early postoperative complications occurred in $10 \%(6 / 60)$ of the patients after sleeve lobectomy, consisting of pneumonia-atelectasis $(n=3)$, empyema $(n=$ $1)$, pulmonary vein thrombosis $(\mathrm{n}=1)$, and myocardial infarction $(\mathrm{n}=1)$.

As late complications after sleeve lobectomy, 2 (3\%) patients had bronchial stricture, but they were both successfully treated with a bronchoscope and did not necessitate any operative repair, such as repeat sleeve resection or completion pneumonectomy. On the other hand, morbidity after pneumonectomy occurred in $22 \%(13 / 60)$ of the patients, consisting of pneumoniaatelectasis $(n=5)$, bronchopleural fistula $(n=4)$, cardiac herniation $(n=2)$, empyema $(n=1)$, and pulmonary infarction $(\mathrm{n}=1)$.

Local recurrence developed in $5(8 \%)$ patients after sleeve lobectomy and in $6(10 \%)$ patients after pneumonectomy.

The 3-, 5-, and 10-year survivals were $61 \%, 48 \%$, and $36 \%$ for patients subjected to sleeve lobectomy and $36 \%, 29 \%$, and $19 \%$ for those subjected to pneumonectomy, respectively (Fig 1). Survival after sleeve lobectomy was significantly longer than that after 


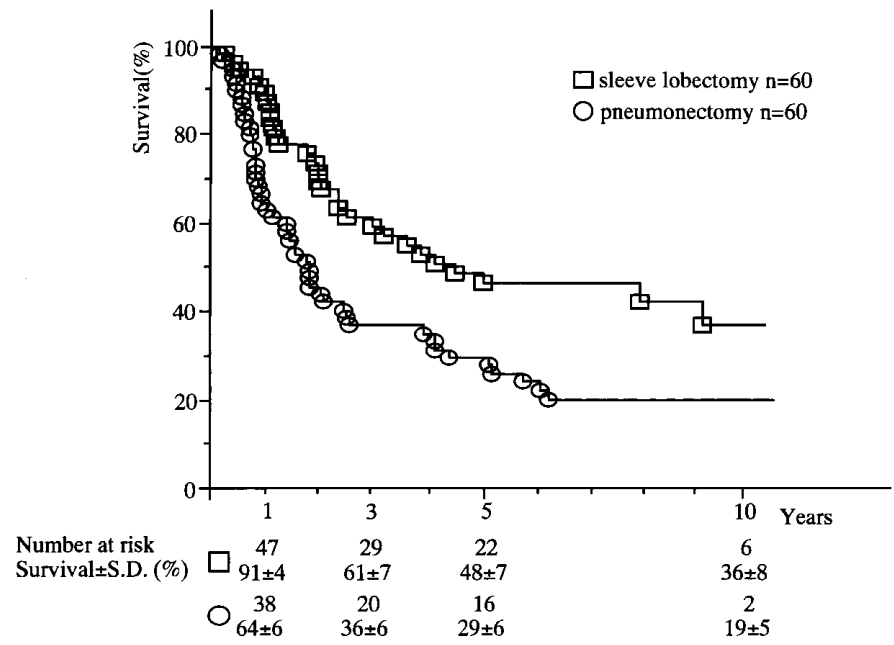

Fig 1. Cumulative survival curves of all patients who underwent complete resection for non-small cell lung cancer according to procedure. The survival of patients subjected to sleeve lobectomy was significantly longer than that of patients subjected to pneumonectomy $(P=.005)$.

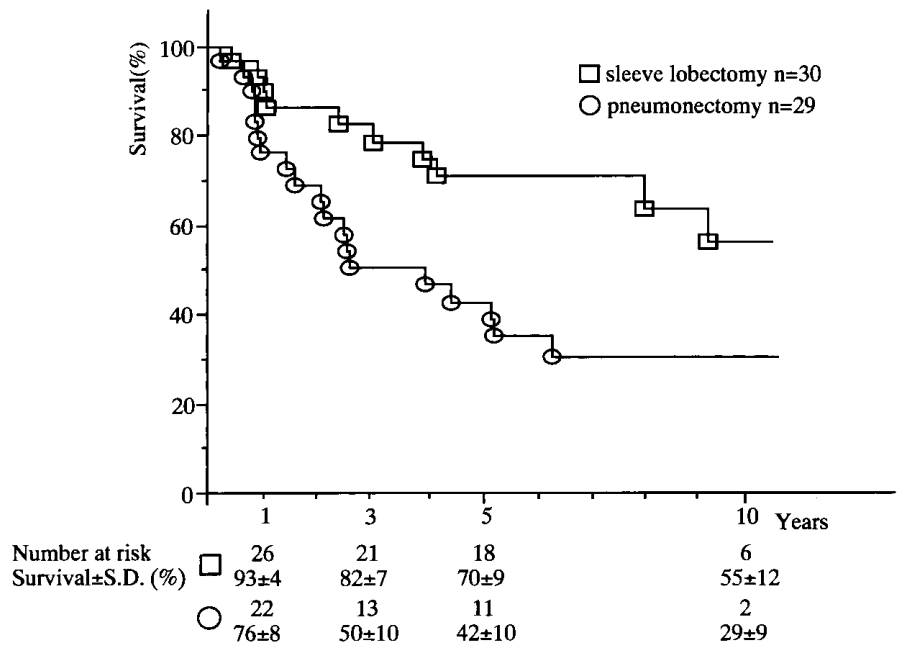

Fig 2. Cumulative survival curves of patients with $\mathrm{pN} 0$ or $\mathrm{pN} 1$ disease who underwent complete resection for non-small cell lung cancer according to procedure. Patients in the sleeve lobectomy group survived significantly longer than those in the pneumonectomy group $(P=.02)$.

pneumonectomy $(P=.005)$. Among patients with N0 or N1 disease, the 3-, 5-, and 10-year survivals were $82 \%, 70 \%$, and $55 \%$ for patients subjected to sleeve lobectomy and $50 \%, 42 \%$, and $29 \%$ for patients who underwent pneumonectomy, respectively (Fig 2). A significant difference between the operative procedures was found among patients with N0 or N1 disease $(P=.02)$. On the other hand, among patients with N2 disease, the 3- and 5-year survivals were 36\% and $21 \%$ for patients who underwent sleeve lobecto- my and $23 \%$ and $16 \%$ for those subjected to pneumonectomy, respectively (Fig 3). Among patients with $\mathrm{N} 2$ disease, there was a trend toward significance, although there was no significant difference $(P$ $=.09$ ). Table II shows the results of the multivariable analysis of independent prognostic factors in patients with sleeve lobectomy or pneumonectomy, demonstrating that patients subjected to sleeve lobectomy had a significantly longer survival than those who underwent pneumonectomy $(P=.03)$. In addition, $\mathrm{T}$ 


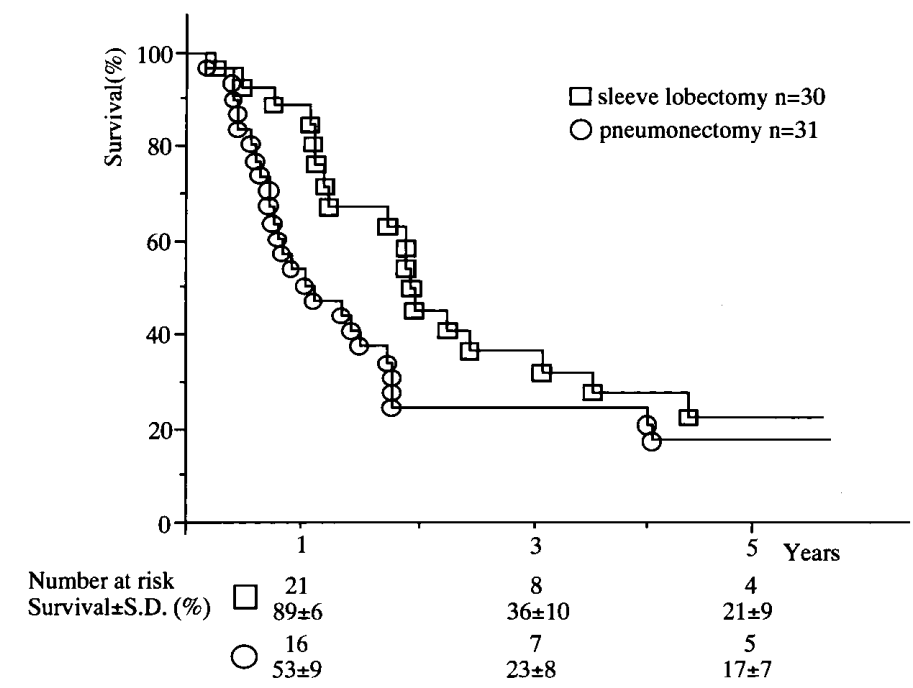

Fig 3. Cumulative survival curves of patients with $\mathrm{pN} 2$ disease who underwent complete resection for non-small cell lung cancer according to procedure. Patients in the sleeve lobectomy group tended to survive longer than those in the pneumonectomy group $(P=.09)$.

Table II. Multivariable analysis of prognostic factors among patients undergoing sleeve lobectomy or pneumonectomy

\begin{tabular}{llllll}
\hline & \multicolumn{2}{c}{ Characteristics } & & & \\
\cline { 2 - 3 } Factors & Unfavorable & Favorable & Risk ratio & 95\% CI & P value \\
\hline Sex & Male & Female & 1.11 & $0.50-2.47$ & .8 \\
Histologic type & non-SQ & SQ & 1.46 & $0.90-2.37$ & .1 \\
pT status & T3,4 & T1,2 & 1.74 & $1.03-2.93$ & .03 \\
pN status & N2 & N0,1 & 2.30 & $1.35-3.92$ & .002 \\
Procedure & PN & SL & 1.73 & $1.05-2.85$ & .03 \\
\hline
\end{tabular}

$C I$, Confidence interval; $S Q$, squamous cell carcinoma; $P N$, pneumonectomy; $S L$, sleeve lobectomy. $S Q$ included patients having pure squamous disease, whereas non-SQ included all other patients, including some with a mixture of cell types, such as adenosquamous carcinoma.

factor $(P=.03)$ and $\mathrm{N}$ factor $(P=.002)$ were shown to be significantly related to survival, and the latter factor affected survival most significantly.

\section{Discussion}

In considering bronchoplasty for selected patients with resectable malignant tumors, we should remember that the decision to perform this procedure depends on an appropriate balance between risks of recurrence plus postoperative complications and postoperative quality of life. Although bronchoplastic procedures were shown to be adequate for about $5 \%$ to $8 \%$ of patients with a resectable pulmonary malignant tumor, ${ }^{13,14}$ we could perform sleeve lobectomy in 13\% (151/1172) of our patients. Because we always keep lung-saving procedures in mind, ${ }^{4,5,15,16}$ pneumonectomy was carried out infrequently compared with sleeve lobectomy. In fact, the frequency of pneumonectomy in our series was low (60/1172 [5\%]). Instead, we have performed bronchoplasty frequently and actively not only in compromised patients but also in noncompromised patients. The reconstructed lobes contribute to postoperative lung function, ${ }^{15}$ and if a second primary lung tumor develops, subsequent resection can be offered. ${ }^{4}$ We have tried various atypical bronchoplasties, such as complex extended sleeve lobectomy involving anastomosis between the main and segmental bronchi with resection of the lobe plus segment, with the purpose of avoiding pneumonectomy. ${ }^{17}$

In any case it is important to keep a macroscopically sufficient margin of safety and to obtain a rapid-frozen section intraoperatively. A major concern regarding bronchoplasty for malignancy might be the potentially increased incidence of local recurrence. The local recurrence after sleeve lobectomy was $13 \%$ in the review of Tedder and colleagues, ${ }^{13} 23 \%$ in the series of 
Mehran and colleagues, ${ }^{1}$ and $20 \%$ in the report of Van Schil and colleagues. ${ }^{2}$ Local recurrence after sleeve lobectomy was found in $8 \%$ of our patients. Compared with pneumonectomy (10\%), sleeve lobectomy was not associated with an increase in local recurrence.

The operative mortality for sleeve lobectomy in the review of Tedder and colleagues ${ }^{13}$ was $6 \%$, and it was $2 \%$ in the series of Mehran and colleagues. ${ }^{1}$ In our series no operative deaths occurred after sleeve lobectomy compared with $2 \%$ operative deaths after pneumonectomy. The rate of postoperative complications was lower after sleeve lobectomy (13\%) than after pneumonectomy (22\%). These data thus indicated the superiority of sleeve lobectomy over pneumonectomy. Pneumonectomy, which limits pulmonary reserve and results in an increased pulmonary artery pressure, leads to greater long-term cardiopulmonary disability and a worse quality of life than does lobectomy. ${ }^{18}$ Also, pneumonectomy has been considered to be a predisposing, although not exclusively causative, factor for cardiopulmonary death. ${ }^{19}$ We therefore consider that pneumonectomy is a disease in itself and should be avoided at all cost.

The relationship between survival after sleeve lobectomy and nodal involvement remains controversial. In our multivariable analysis, nodal status was the most significant factor related to survival, with $\mathrm{N} 2$ disease having a definitely negative effect compared with N0 or N1 disease. Mehran and colleagues ${ }^{1}$ demonstrated a significant difference in survival between $\mathrm{N} 1$ and $\mathrm{N} 2$ disease but not between $\mathrm{N} 0$ and $\mathrm{N} 1$ disease after sleeve resection and reported acceptable long-term prognosis in patients undergoing sleeve resection for lung cancer with N1 disease but not with $\mathrm{N} 2$ disease. Although the 5-year survival for patients with N2 disease after sleeve resection was shown to be $0 \%$ by Mehran and colleagues, ${ }^{1}$ it was $33 \%$ in the series of Naruke $^{20}$ and $31 \%$ in the report of Van Schil and colleagues. ${ }^{2}$ The indication of sleeve lobectomy for patients with $\mathrm{N} 2$ disease (stage IIIA) is controversial and requires circumspection. We, however, do not think that pneumonectomy instead of sleeve lobectomy would have resulted in longer survival for patients with $\mathrm{N} 2$ disease because the cause of death in patients with $\mathrm{N} 2$ disease was mainly distant metastasis and not local recurrence.

Our multivariable analysis revealed that patients subjected to sleeve lobectomy could have a significantly better prognosis than those subjected to pneumonectomy regardless of sex, histologic type, $\mathrm{pN}$ factor, or $\mathrm{pT}$ factor. It was possible that patients who underwent pneumonectomy would have bigger more central tumors or more nodes involved, even if the stage was the same, which could affect the survival. In addition, the poor survival of patients with pneumonectomy might be due to functional or non-cancer-related reasons. This study demonstrated that sleeve lobectomy was a suitable surgical treatment for non-small cell lung cancer in terms of both operative risks and curability to say nothing of postoperative pulmonary function. We suggest that sleeve lobectomy should be performed for centrally located lung cancer whenever removal of the lesions is complete because this procedure accomplished a curability comparable with that of pneumonectomy, with the possible advantages of lower operative mortality and morbidity, equal if not better survival, and improved quality of life.

\section{REFERENCES}

1. Mehran RJ, Deslauriers J, Piraux M, Beaulieu M, Guimont C, Brisson J. Survival related to nodal status after sleeve resection for lung cancer. J Thorac Cardiovasc Surg 1994;107:576-83.

2. Van Schil PE, Riviere AB, Knaepen PJ, Swieten HA, Reher SW, Goossens DJ, et al. Long-term survival after bronchial sleeve resection: univariate and multivariate analyses. Ann Thorac Surg 1996;61:1087-91.

3. Gaissert HA, Mathisen DJ, Moncure AC, Hilgenberg AD, Grillo HC, Wain JC. Survival and function after sleeve lobectomy for lung cancer. J Thorac Cardiovasc Surg 1996;111:948-53.

4. Okada M, Tsubota N, Yoshimura M, Miyamoto Y. Surgical approach for multiple primary lung carcinomas. J Thorac Cardiovasc Surg 1998;115:836-40

5. Okada M, Tsubota N, Yoshimura M, Miyamoto Y, Matsuoka H. Prognosis of completely resected pN2 non-small cell lung carcinomas. What is the significant node that affects survival? J Thorac Cardiovasc Surg 1999;118:270-5.

6. Yoshino I, Yokoyama H, Yano T, Ueda T, Takai E, Mizutani K, et al. Comparison of the surgical results of lobectomy with bronchoplasty and pneumonectomy for lung cancer. J Surg Oncol 1997;64:32-5.

7. Okada M, Tsubota N, Yoshimura M, Miyamoto Y, Maniwa Y. Role of pleural lavage cytology before resection for primary lung carcinomas. Ann Surg 1999;229:579-84.

8. World Health Organization histologic typing of lung turnouts. 2nd ed. Am J Clin Pathol 1982;77:123-36.

9. Mountain CF. Revisions in the international system for staging lung cancer. Chest 1997;111:1710-7.

10. D'Agostino RB Jr. Propensity score methods for bias reduction in the comparison of a non-randomized control group. Stat Med 1998;17:2265-81.

11. Kaplan E, Meier P. Nonparametric estimation from incomplete observations. J Am Stat Assoc 1958;53:457-81.

12. Cox DW. Regression models and life tables. J R Stat Soc 1972; 34:187-220.

13. Tedder M, Anstadt M, Tedder S, Lowe JM. Current morbidity, mortality, and survival after bronchoplastic procedures for malignancy. Ann Thorac Surg 1992;54:387-91.

14. Lowe JE, Sabiston DC Jr. Bronchoplastic techniques in the surgical management of benign and malignant pulmonary lesions In: Sabiston DC Jr, Spencer FC, editors. Surgery of the chest. Philadelphia: WB Saunders; 1990. p. 577.

15. Tsubota N, Yoshimura M, Murotani A, Miyamoto Y, Matoba Y. 
One hundred and one cases of bronchoplasty for primary lung cancer. Surg Today 1994;24:978-81.

16. Okada M, Tsubota N, Yoshimura M, Miyamoto Y. Proposal for reasonable mediastinal lymphadenectomy in bronchogenic carcinomas: role of subcarinal node in selective dissection. J Thorac Cardiovasc Surg 1998;116:949-53.

17. Okada M, Tsubota N, Yoshimura M, Miyamoto Y, Matsuoka H, Satake S, et al. Extended sleeve lobectomy for lung cancer to avoid pneumonectomy. J Thorac Cardiovasc Surg 1999;118:710-4.
18. Rocco PM, Antkowiak JG, Takita H, Urschel JD. Long-term outcome after pneumonectomy for nonsmall cell lung cancer. J Surg Oncology 1996;61:278-80.

19. Shields TW, Humphrey EW, Higgins GA, Keehn RJ. Long-term survivors after resection of lung carcinoma. J Thorac Cardiovasc Surg 1978;76:439-45.

20. Naruke T. Bronchoplastic and bronchovascular procedures of the tracheobronchial tree in the management of primary lung cancer. Chest 1989;96(Suppl):53S-6S.

\section{Authoritative}

The Journal of Thoracic and Cardiovascular Surgery is the most frequently cited thoracic/cardiovascular surgery journal in the Science Citation Index. An article in JTCVS is sited on average almost twice as often as those in the closest cardiothoracic journal. 